\title{
LOOP ECONÔMICO: MERCADO IMOBILIÁRIO INFLUÊNCIA E É INFLUENCIADO PELAS CONDIÇÕES SOCIOECONÔMICAS
}

\author{
Alexandre Godinho Bertoncello, Aline Zanoni Ramos, Gustavo Tressino Campos, Henrique Pineda Torquato
}

Universidade do Oeste Paulista - UNOESTE. E-mail: bertoncello@unoeste.br

\section{RESUMO}

O cenário imobiliário no país atrai a atenção de pequenos e grandes investidores, porém a imprevisibilidade deste mercado pode prejudicar o desempenho do investidor de imóveis e das empresas que dependem desse bem para estabelecer seus investimentos. Com o agravante de não existir um índice regional para o Oeste Paulista, a região fica ainda mais vulnerável às possíveis oscilações que não conseguem ser acompanhadas de forma sistêmica. $O$ trabalho tem por objetivo a coleta de dados para evidenciar e proporcionar uma análise sobre o impacto dos preços dos imóveis urbanos, rurais e comerciais através de um índice que possa ser comparado com outros fatores econômicos para que assim a informação seja condizente com a realidade regional. Dada a ausência de uma metodologia regional, a proposta apresentada foi criada especificamente para a região e, o método de pesquisa ficou definido como quantitativo de caráter exploratório-descritivo, com levantamento de dados semanais. Para cada tipo de imóvel (urbanos, rurais e comerciais), foram escolhidas as 6 cidades mais relevantes nos quesitos: maior população, maior extensão territorial e maior quantidade de comércios, respectivamente. De acordo com os resultados obtidos, pode-se afirmar que há um potencial imobiliário no Oeste Paulista devido ao aquecimento do setor urbano em reflexo do cenário socioeconômico, a sensação de melhora da segurança jurídica estabeleceu novos valores para terras devolutas no setor rural e o setor comercial aponta junto com o cenário de melhora na economia para novos patamares expressivamente melhores para a região.

Palavras-Chave: índices imobiliários; imóveis urbanos; imóveis rurais; imóveis comerciais.

\section{ECONOMIC LOOP: REAL ESTATE MARKET INFLUENCES AND IS INFLUENCED BY SOCIOECONOMIC CONDITIONS. \\ ECONOMIC LOOP AND THE REAL ESTATE MARKET.}

\begin{abstract}
The real estate scenario in the country attracts the attention of small and large investors, but the unpredictability of this market may undermine the performance of the real estate investor and the companies that depend on it to establish their investments. With the aggravation of the lack of a regional index for the Oeste Paulista, the region is even more vulnerable to possible oscillations that cannot be systemically monitored. The purpose of this paper is to collect data to highlight and provide an analysis of the impact of urban, rural and commercial property prices through an index that can be compared with other economic factors so that the information is consistent with the regional reality. Given the absence of a regional methodology, the proposal was created specifically for the region and the research method was defined as a quantitative exploratory-descriptive, with weekly data collection. For each type of property (urban, rural and commercial), the 6 most relevant cities were chosen in terms of a larger population, larger territorial extension and larger trade amount, respectively. According to the results obtained, it can be said that there is a potential real estate in the region called Oeste Paulista due to the warming of the urban sector reflecting the socioeconomic scenario, the feeling of improved legal certainty established new values for vacant land in the rural sector and the commercial sector points with the scenario of improvement in the economy to significantly new levels for the region.
\end{abstract}

Keywords: real estate indexes; urban real estate; rural real estate; commercial real estate. 


\section{INTRODUÇÃO}

O mercado imobiliário tem relevante peso no cenário econômico de qualquer país, ele pode impactar negativamente ou positivamente os níveis, micro e macroeconômicos, proporcionando um loop econômico de difícil identificação da causa e do efeito.

A crise do subprime nos Estados Unidos causou uma drástica queda nos preços imobiliários daquele país, ela foi potencializada, ao ponto de modificar a estrutura monetária global, de forma negativa e viciosa, após a crise (DEMYANYK; HEMERT, 2011). Ao mesmo tempo, os investimentos públicos e privados no setor imobiliário na China colaboraram de forma significativa para o crescimento da economia chinesa durante 2 décadas ininterruptas, demonstrando como o setor imobiliário pode induzir a crescimentos significativos (MOSTAFA; WONG; HUI, 2006).

Investimentos na compra ou na construção de imóveis, tem duas características, diminui a liquidez dos envolvidos e cria obrigações de longo prazo, fomentando uma interdependência monetária entre compradores, vendedores e financiadores.

Em São Paulo, entre 2005 e 2010, houve um aumento de unidades vendidas e ao mesmo tempo aumento do valor do metro quadrado demonstrando, ganhos de toda a cadeia, inclusive os compradores, que apesar de pagarem juros relativamente altos, tiveram uma valorização dos seus imóveis em percentuais maiores que as taxas de juros existentes (JP Morgan, 2011).

Gráfico 1. Preço e unidades vendidas.

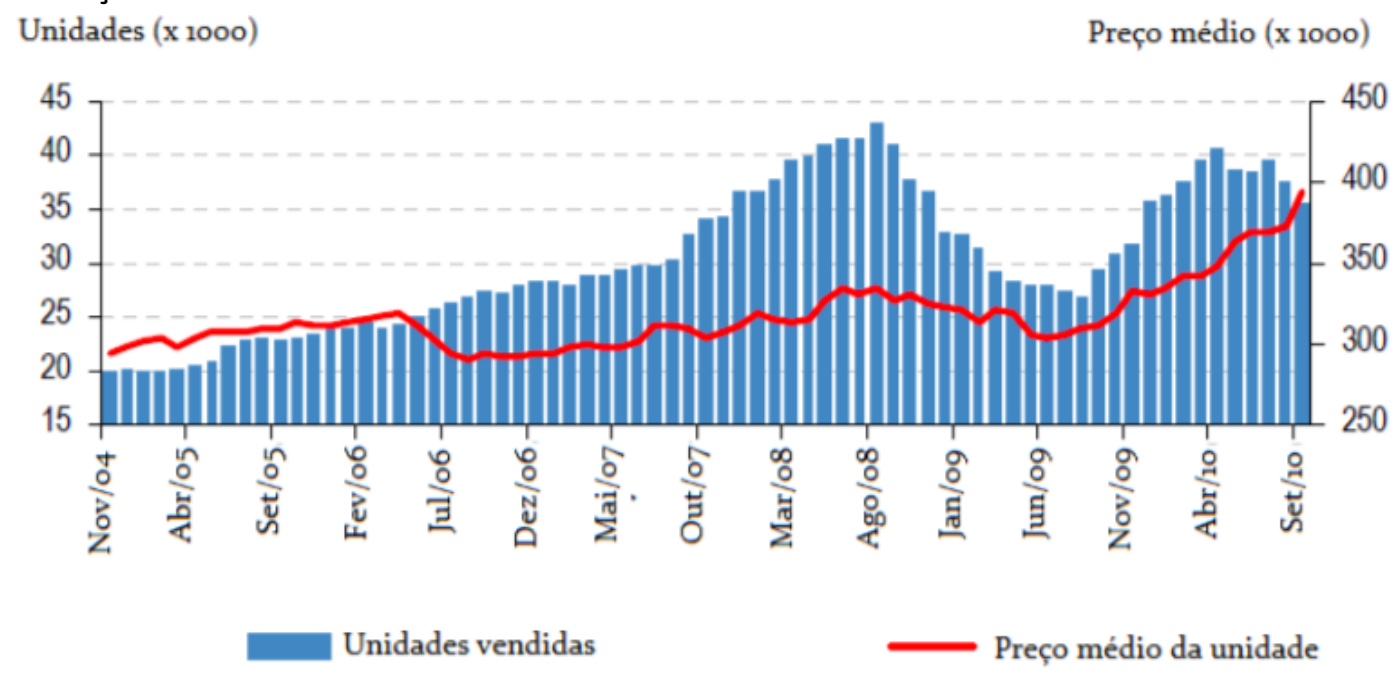

Fonte: JP Morgan, 2011.

Este cenário mudou drasticamente, após a crise de 2014/15, segundo o site da FIPE $^{1}$ o mercado imobiliário no Brasil, passou a perder rendimento e obter ganhos inferiores a inflação, demonstrando uma perda real de $17,31 \%$ entre junho de 2012 e dezembro de 2018.

\footnotetext{
1 http://fipezap.zapimoveis.com.br
} 
Gráfico 2. IPCA e valorização dos imóveis.

FIPEZAP VENDA: 29.14\% - jun 2012 a dez 2018

- IPCA: $46.45 \%$ - jun 2012 a dez 2018

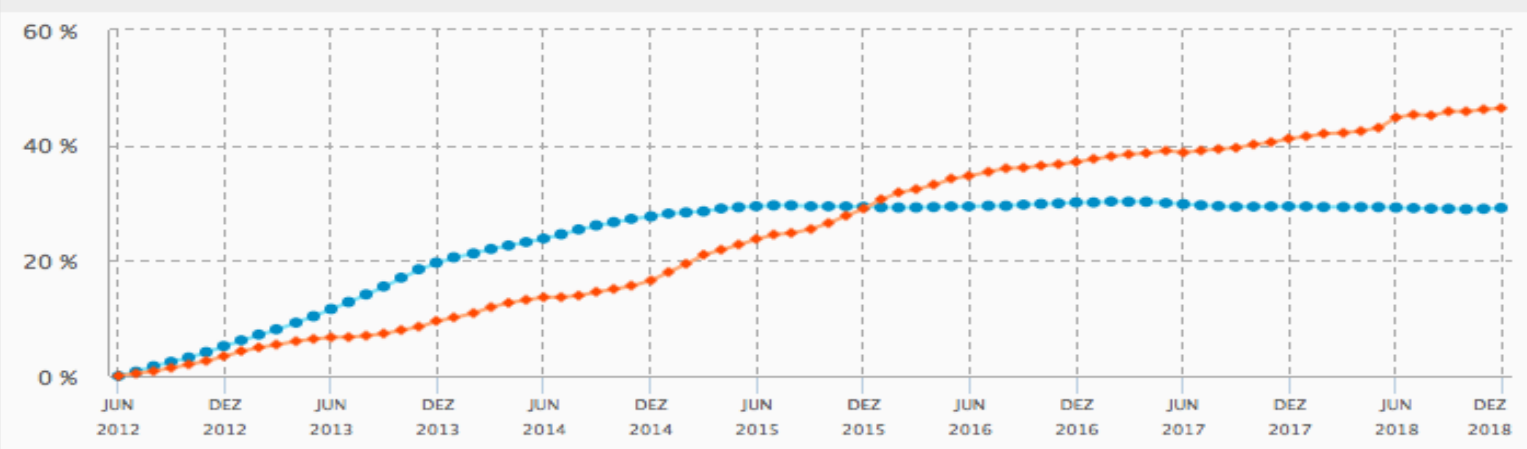

Fonte: FIPEZAP, 2019.

Buscou-se nesta pesquisa analisar os métodos utilizados a nível nacional, criar um método regional com metodologias similares para as áreas rurais, residenciais e comerciais urbanas. Desta forma, monitorar as tendências de mercado para compreender oportunidades e ameaças do setor para os atores envolvidos.

\section{MÉTODOS}

A metodologia aplicada é a quantitativa de caráter exploratório-descritivo, com levantamento bibliográfico.

Segunda a definição no estudo realizado por Fonseca (2002, p. 20):

“Diferentemente da
pesquisa qualitativa, os
resultados da pesquisa
quantitativa podem ser
quantificados. Como as
amostras geralmente são
grandes e consideradas
representativas da
população, os resultados
são tomados como se
constituíssem um retrato
real de toda a população
alvo da pesquisa. A
pesquisa quantitativa se
centra na objetividade.
Influenciada pelo
positivismo, considera que
a realidade só pode ser
compreendida com base
na análise de dados
brutos, recolhidos com o
auxílio de instrumentos
padronizados e neutros. A
pesquisa quantitativa
recorre à linguagem

matemática para descrever as causas de um fenômeno, as relações entre variáveis, etc."

O levantamento de dados da pesquisa que ocorreu entre os anos de 2018 e 2019, envolveu uma ampla quantidade de dados coletados no período de um ano, foram computados 46.907 dados, a amostragem relevante possibilita representar com objetividade o cenário em questão. Recortado a forma de coleta e obtendo-se dados suficiente é possível, através de cálculos, gráfico e comparações com índices da economia, traçar comparativos de como esses dados foram influenciados.

Segundo Gil (2008) as pesquisas exploratórias são a primeira etapa de uma ampla pesquisa e habitualmente com o uso bibliográfico, já o final dela passa a ser um processo mais aprimorado, com procedimento e um método direcionado, o autor explica o método descritivo consiste em estudar as características de um grupo específico.

Essa pesquisa procurou transformar os dados regionais em informação relevante, por meio de uma coleta programática e constante focada em imóveis urbanos residenciais, comerciais e imóveis rurais. Para tal, a amostra de 53 cidades da Região do Oeste Paulista, teve alguns filtros metodológicos estabelecidos:

- Para o Índice Urbano, foram escolhidas as 6 cidades com a maior quantidade populacional estimada; 
- Para o Índice Rural, foram escolhidas as 6 cidades com a maior área de extensão territorial rural e;

- Para o Índice Comercial, foram escolhidas as 6 cidades com maior número de empresas atuantes.

Destaca-se que, definido os critérios, os dados foram coletados no site do IBGE (Instituto Brasileiro de Geografia e Estatística).

A fonte para a coleta de dados foram os sites: OLX, Zaplmóveis, MarketPlace (Facebook) e ImóvelWeb. E a coleta de dados foi sistematizada e coletada em uma periodicidade semanal, sempre nos finais de semana. Para cada categoria de imóveis, foi dividido os tipos de imóveis coletados em:

- Urbano - Terreno, casa, sobrado e apartamento;

- Rural - rancho, sítio, chácara e fazenda; e

- Comercial - casa comercial, sala comercial, galpão/barracão, hotel, posto de gasolina, lanchonete, entre outros.

Com os dados coletados no período de um ano, sendo eles os preços dos imóveis e seu tamanho, em metros quadrados para os imóveis urbanos e comerciais e em hectares para os rurais, calculou-se o preço médio a cada dia de coleta para fazer as projeções de comportamento desses preços no decorrer do tempo.

Para os imóveis urbanos, as cidades estabelecidas foram: Adamantina, Dracena, Osvaldo Cruz, Presidente Epitácio, Presidente Prudente e Presidente Venceslau. Averiguados mensalmente, foram separados para a comparação com o cenário político-econômico em cada situação.

Com os imóveis rurais, as cidades definidas foram: Marabá Paulista, Martinópolis, Mirante do Paranapanema, Presidente Epitácio, Rancharia e Teodoro Sampaio. Os dados foram analisados mês a mês e comparados, para observar os problemas estruturais de terras devolutas e não devolutas. Dentre as seis cidades escolhidas, duas possuem terras sem problemas de regulamentação que são Martinópolis e Rancharia, e quatro com problemas de terras não regulamentadas, são elas Marabá Paulista, Mirante do Paranapanema, Presidente Epitácio e Teodoro Sampaio.

Já com os imóveis comerciais, as cidades selecionadas foram: Adamantina, Dracena, Osvaldo Cruz, Presidente Epitácio, Presidente Prudente e Presidente Venceslau. Posteriormente, esses dados foram separados de forma trimestral seguindo o mesmo período que se é calculado o PIB (Produto Interno Bruto) no Brasil, e feito uma comparação à ele.

\section{RESULTADOS}

Para cada modalidade de imóvel, sendo estes urbanos, rurais e comerciais como já mencionados anteriormente, obteve-se dados totalmente particulares para a categoria. Desta forma, após fazer a aglomeração dos dados específicos cada índice foi definido como influenciador direto dos pares.

Em um primeiro momento foi calculada a média dos dados coletados por cidade, em seguida a média semanal, para chegar à média mensal dos imóveis urbanos e rurais, e a média trimestral dos imóveis comerciais:

$$
\underline{x}=\frac{d 1+d 2+\ldots+d n}{n}
$$

Onde cada amostra possui uma quantidade $n$ de dados, e assim, para aplicar a fórmula da média nesses dados: $d 1+$ $d 2+\ldots .+d n$, são somados e o resultado dessa soma é dividido pela quantidade de dados total $(n)$. Dessa forma, tem-se a média de cada período de amostras que posteriormente é utilizada, em conjunto com a demais médias, para se chegar no resultado final e passível de verificações.

Para ter maior representatividade dos dados, é necessário aplicar o peso que cada cidade tem no montante total de cada fator escolhido, sendo a quantidade populacional para o urbano, a extensão territorial para o rural e o número de comércios para o comercial:

$$
y=\frac{\beta}{\rho}
$$

Onde $\beta$ é o dado da cidade em questão, $\rho$ é a soma total do fator definido e $y$ é o peso da respectiva cidade.

Após definidas as médias a serem utilizadas e chegado ao peso que cada cidade tem em relação ao montante total, faz-se a média ponderada com os dados em questão:

$$
I=\underline{x_{1}} \cdot y_{1}+\underline{x_{2}} \cdot y_{2} \ldots \underline{x_{n}} \cdot y_{n}
$$

Onde $x_{n}$ é a média feita anteriormente, $y_{n}$ o peso de cada cidade conforme encontrada e I o valor final do índice. 


\section{IMÓVEIS URBANOS}

Separando os dados obtidos de forma mensal e os comparando com o cenário políticoeconômico do país chega-se à conclusão de que no decorrer de agosto a outubro de 2018 houve um crescimento constante, e o preço do metro quadrado dos imóveis urbanos subiram em $13,25 \%$.

Porém, em novembro e dezembro do mesmo ano, houve uma queda de $1,43 \%$ e $2,24 \%$ respectivamente, que prejudicou o ganho do setor em 2018, conforme análise do gráfico 3 . Este desequilíbrio, entre oferta e demanda, inverteu-se novamente no início do 10 semestre de 2019 , os preços voltaram a subir até o final do mesmo, resultando em um aumento de preços na ordem de $4,78 \%$ em relação ao semestre anterior, conforme disposto no gráfico 4 .

Gráfico 3. Oscilação dos preços da média da região de imóveis do Oeste Paulista.

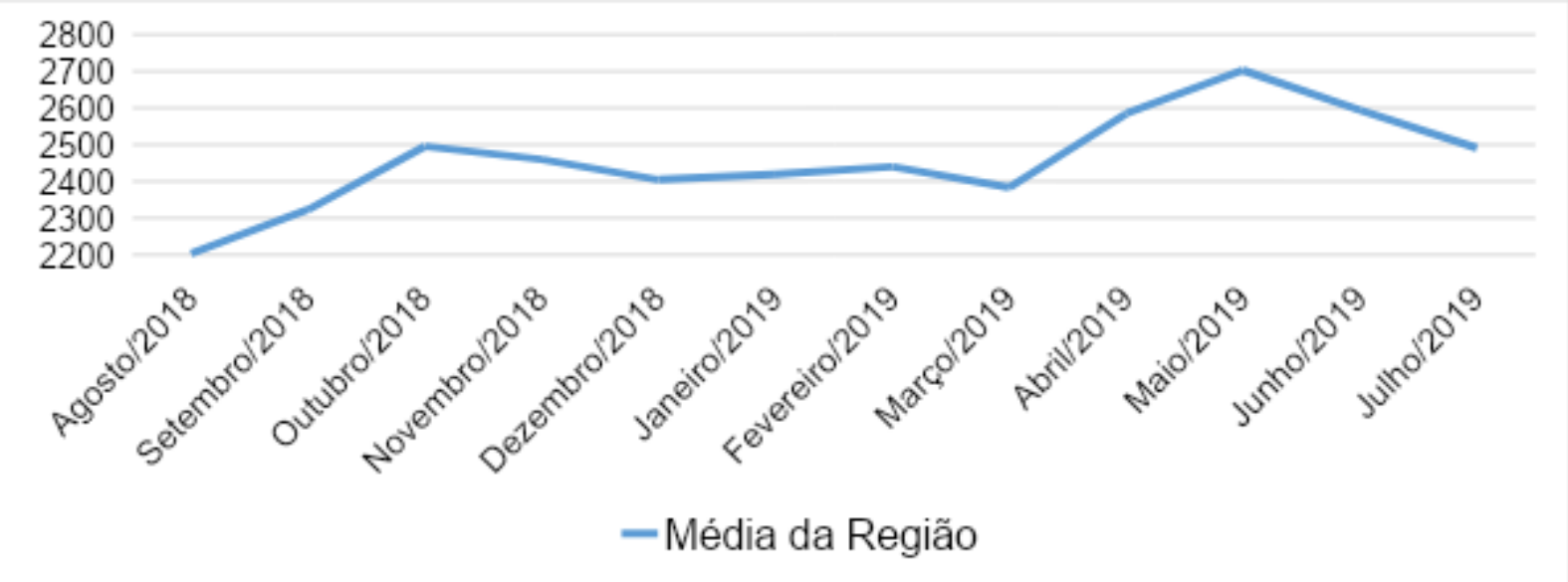

Fonte: Os autores (2019)

Observa-se a oscilação de todas as cidades estabelecidas como indicadoras para a região isoladamente, fica difícil observar o comportamento do cenário como um todo devido às peculiaridades de cada localidade, como mostra o gráfico abaixo, onde Presidente
Prudente e Presidente Epitácio destacam-se positivamente enquanto a maior queda proporcional é de Presidente Venceslau.

Gráfico 4. Oscilação dos preços dos imóveis nas cidades mais populosas do Oeste Paulista.

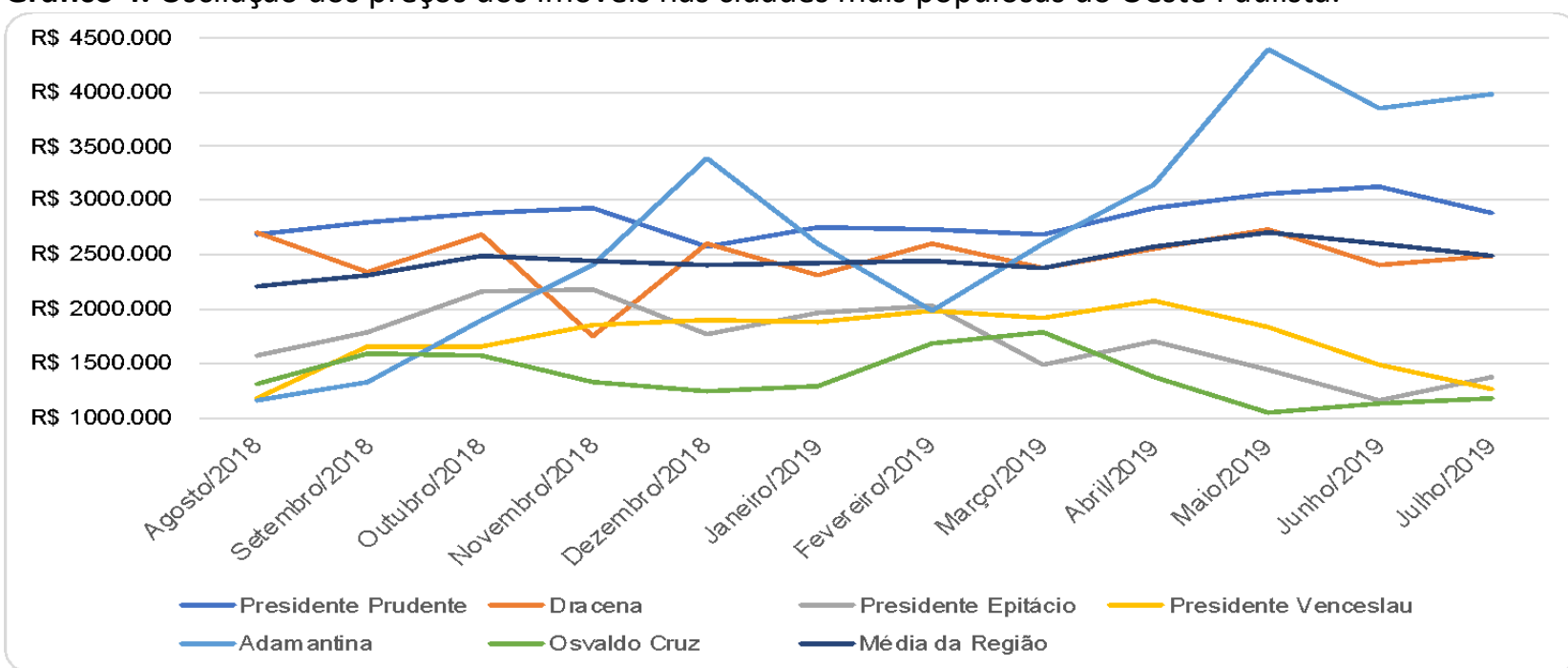

Fonte: Os autores (2019) 
Movimentos semelhantes aos das casas, ocorreu com os terrenos urbanos na região, é possível observar oscilações de preços no 2 은 semestre de 2018, com quedas em outubro e dezembro, mas que não afetaram a valorização do período, que obteve um aumento de $16,53 \%$ no final do ano. Em 2019 a tendência de alta se intensificou e obteve-se ganhos expressivos e em julho de 2019 o metro quadrado chegou a $\mathrm{R} \$$ 550,82 .

Gráfico 5. Oscilação dos preços da média da região de terrenos do Oeste Paulista.

$R \$ 600.000$

$\mathrm{R} \$ 550.000$

$\mathrm{R} \$ 500.000$

$R \$ 450.000$

$\mathrm{R} \$ 400.000$

$\mathrm{R} \$ 350.000$

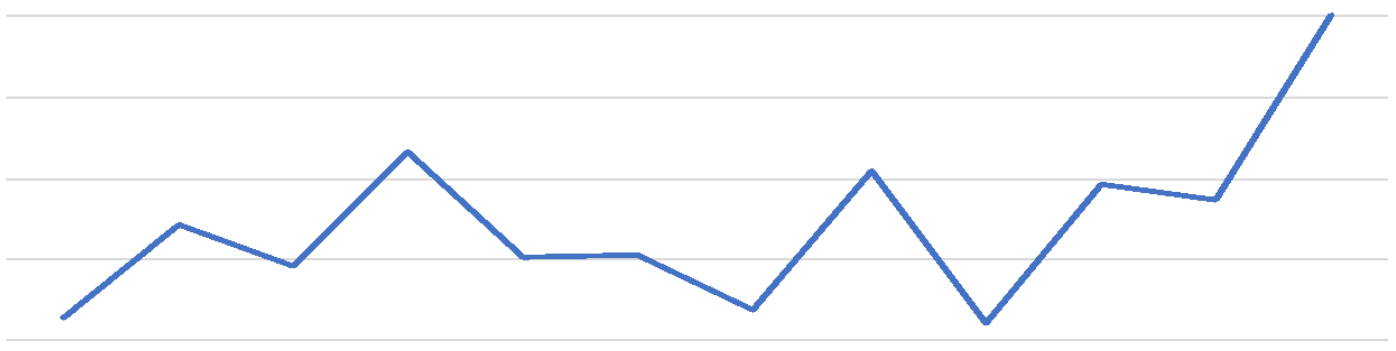

$\mathrm{R} \$ 300.000$

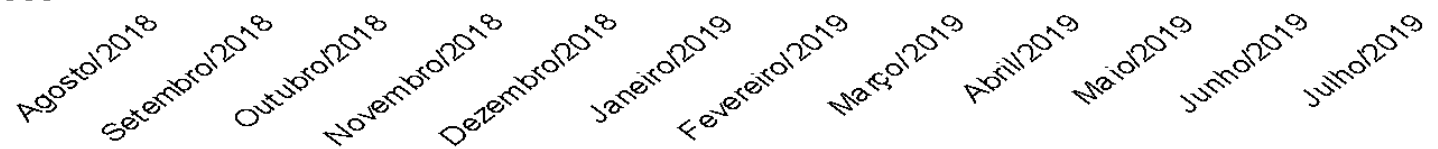

Média da Região

Fonte: Os autores (2019)

O gráfico 6 evidencia o que foi dito acima, onde é notável a valorização dos terrenos na região do Oeste Paulista desde o início das coletas de dados há 1 ano até o início deste 20 semestre de 2019. Mas estratificando os dados nota-se ganhos significativos em Presidente Prudente e Presidente Epitácio enquanto Adamantina teve uma queda de preços.

Gráfico 6. Oscilação dos preços dos terrenos nas cidades mais populosas do Oeste Paulista.

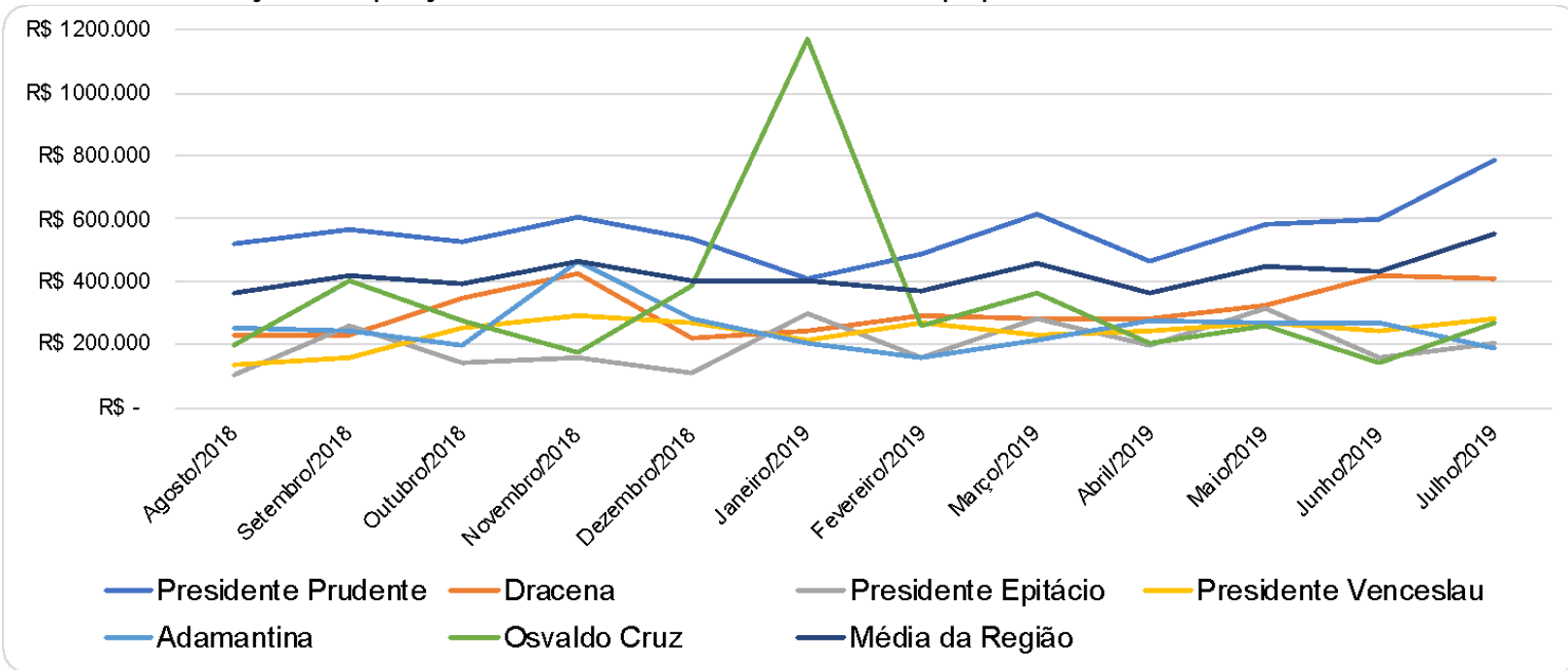

Fonte: Os autores (2019) 


\section{IMÓVEIS RURAIS}

O índice de imóveis rurais foi criado considerando a disponibilidade de terra dos 6 maiores municípios em extensão territorial. $\mathrm{Na}$ sociedade rural considera-se, utilizando uma figura de linguagem explicativa, que as terras que se encontram abaixo da rodovia Raposo Tavares até a divisa com Mato Grosso do Sul, são em grande quantidade terras devolutas. $\mathrm{Na}$ amostragem das cidades escolhidas para o novo retrato rural do Oeste Paulista, tem-se terras com problemas de regulamentação nas cidades de Marabá Paulista, Mirante do Paranapanema, Presidente Epitácio e Teodoro Sampaio, e terras regulamentadas representadas pelas cidades de Martinópolis e Rancharia.

Dois fatos importantes foram descobertos: Primeiro, as expectativas de mudanças sociais, provavelmente impulsionaram o valor do hectare de agosto até dezembro de 2018 na região, porém esta tendência se modificou em 2019 e reduziram-se os ganhos, entretanto o índice demonstra um ganho do valor nominal de 53,95\% em um ano. Segundo, estes ganhos foram significativos em cidades com histórico de terras devolutas, o valor médio do hectare nestas cidades saltou de $\mathrm{R} \$ 8.956,38 \mathrm{em}$ agosto de 2018, para $\mathrm{R} \$ 26.895,25$ em julho de 2019, por outro lado, as cidades sem esse problema o valor da terra teve um decréscimo de R\$ $33.160,55$ para R\$ 28.101,23 no mesmo período. Mas as terras regularizadas continuaram tendo um valor superior as contrárias.

Gráfico 7. Variação dos preços, por hectare, das propriedades no período.

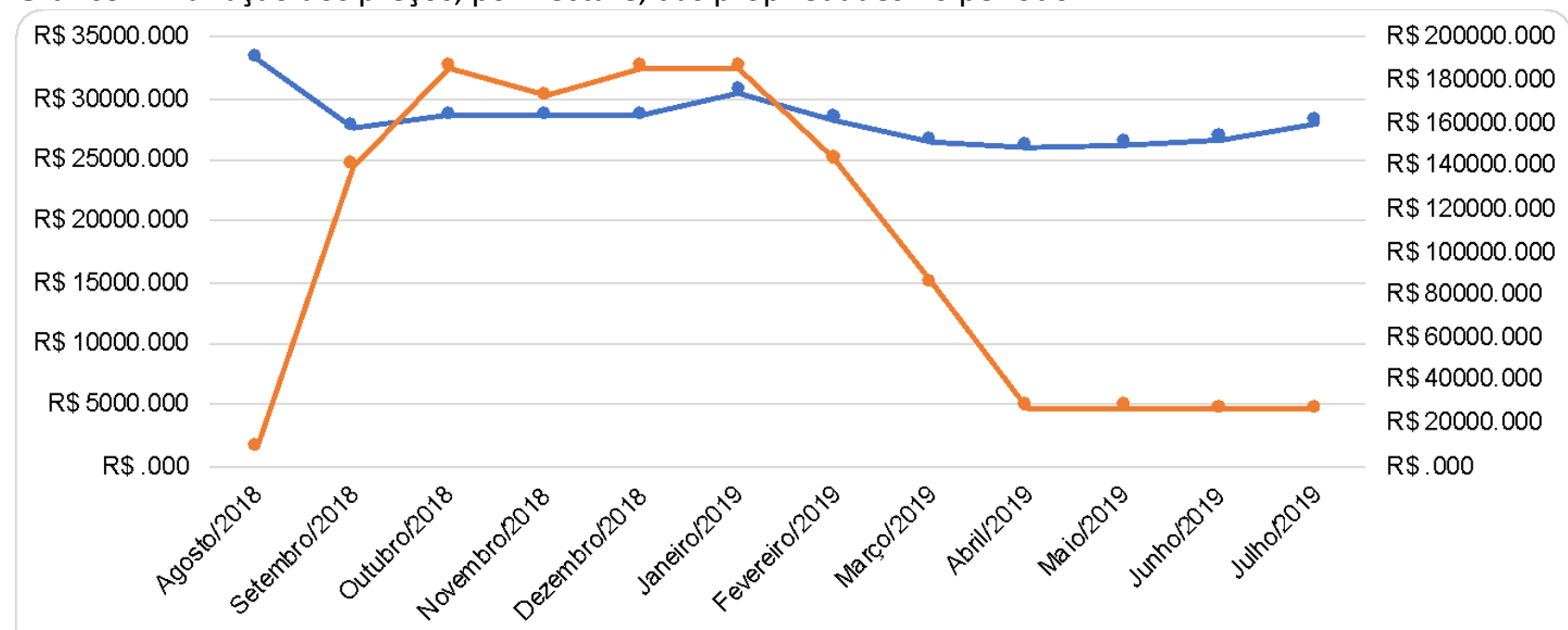

$\multimap$ Média de terras não devolutas $\quad \multimap$ Média de terras devolutas

Fonte: Os autores (2019)

\section{IMÓVEIS COMERCIAIS}

Assumindo a hipótese que os imóveis comerciais terão influência na economia de cada cidade e que o comportamento dos preços de bens e serviços da região vai induzir o comportamento dos preços imobiliários em um clássico movimento de um modelo gravitacional (BERTONCELLO; Ó SOUZA, 2018), foi definido fazer a comparação das oscilações dos preços dos imóveis com o PIB (Produto Interno Bruto) do país, verificando assim, como as reais oscilações da economia brasileira pode afetar nos preços dos imóveis comerciais da região do Oeste Paulista.

Segundo é apresentado pelo IBGE, (2019), “O PIB é a soma de todos os bens e serviços finais produzidos por um país, estado ou cidade, geralmente em um ano. Todos os países calculam o seu PIB nas suas respectivas moedas".

Dessa forma, o PIB é o índice que melhor reflete como o mercado de bens e serviços do Brasil está se comportando, por isso definiu-se para esta pesquisa e especificamente para os imóveis do setor comercial como o melhor 
indicativo de comparação das oscilações dos preços pelos dados objetos.

Esses dados foram separados de forma trimestral, seguindo o mesmo período que se é apurado o PIB no Brasil. Como descrito, o objetivo foi identificar como a economia no país tende a impactar diretamente nos preços desses imóveis e a rentabilidade dos investimentos.

O PIB no 2o trimestre de 2018 era de 0,91 , no trimestre seguinte o PIB subiu para 1,27, tendo um aumento de $39,56 \%$, com a maior expectativa de crescimento, os preços dos imóveis aumentaram $13,55 \%$ no período do 3 은 para o 4 ㅇ trimestre de 2018 .

Após isso, o PIB teve queda para 1,08 no 40 trimestre, sendo ela de $14,96 \%$, refletindo na redução de $16,66 \%$ nos preços dos imóveis no 1 응 trimestre de 2019. Nesse caso a queda de ambos foi proporcionalmente similar, se aproximando muito percentualmente uma da outra.
Este fenômeno de queda se repetiu no próximo trimestre, o PIB continuou a cair e fechou em 0,46 no 1 o trimestre de 2019, uma queda de $57,41 \%$ dessa vez, e o preço dos imóveis também teve mais uma queda no 2 o trimestre de 2019, sendo essa de 4,16\%. Dessa vez, apesar de ambos terem caído, elas não foram proporcionalmente parecidas, tendo uma grande diferença em porcentagens.

Seguindo essa perspectiva foi feita uma projeção do PIB desde o 20 trimestre de 2018 até o 1 o trimestre de 2019 , visto que até o momento da elaboração deste artigo é o último apurado e divulgado, e o que antecede aos dados coletados, que vão até o 2o trimestre de 2019. Sendo assim foi possível analisar como a variação de cada trimestre do PIB afeta na variação do trimestre seguinte nos preços dos imóveis comerciais.

Gráfico 8. Variação do PIB por trimestre.

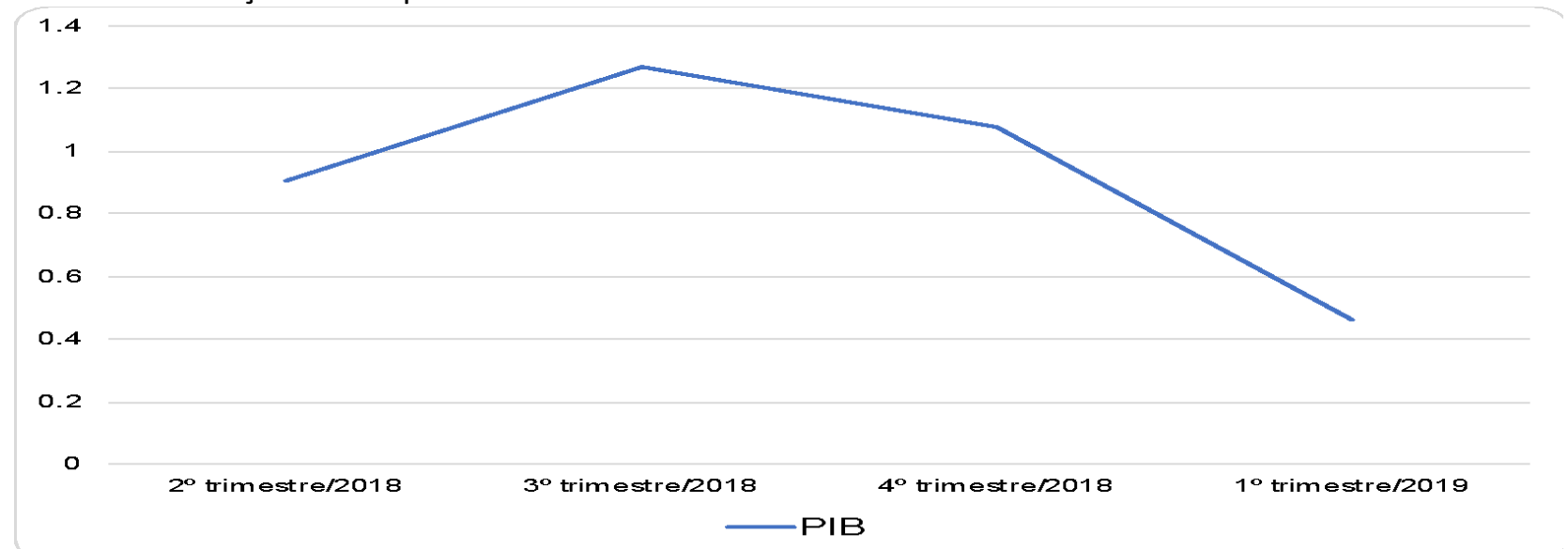

Fonte: IPEADATA, 2019

Nota: Adaptada pelos autores, (2019)

Assim como feito com os dados do PIB, tem-se também o gráfico das oscilações dos preços dos imóveis comerciais de cada umas das cidades definidas para servirem como parâmetro da média da região. Além das cidades foi feita também a média da região, aplicando o respectivo peso da quantidade de comércios de cada uma, de forma de que as cidades com mais comércios, ou seja, mais dados projetam mais no índice e respectivamente no gráfico. 
Gráfico 9. Variação dos preços das cidades e da média da região nos trimestres.

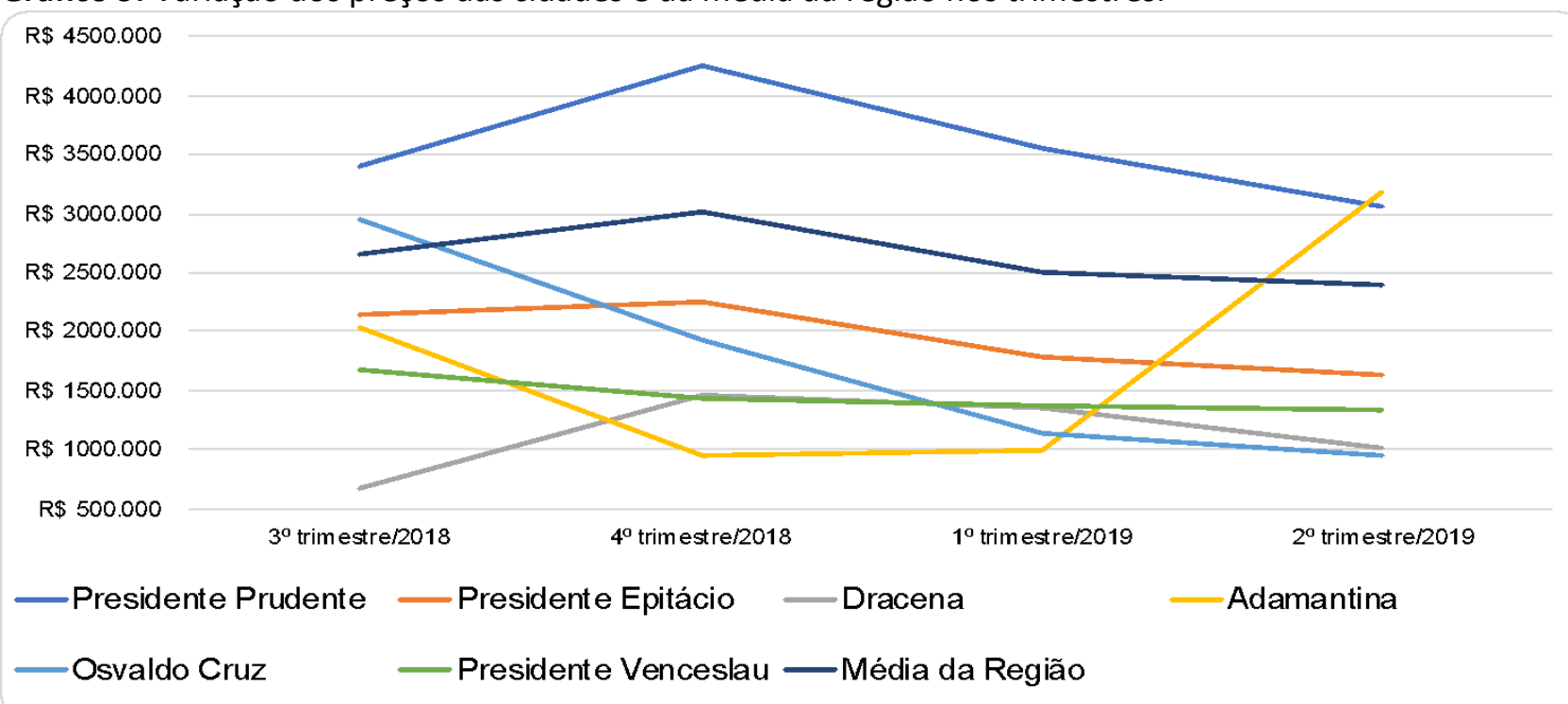

Fonte: Os autores (2019)

A partir dos gráficos se observa mais claramente uma forte relação da oscilação do PIB com a dos preços dos imóveis comerciais do Oeste Paulista, tendo sempre a projeção do aumento ou queda do PIB no trimestre seguinte dos preços.

Vale ressaltar também que apesar de algumas cidades não seguirem o mesmo padrão que a média da região, elas influenciam diretamente na formação dela, cada uma com seu respectivo peso sobre a média geral. Dessa forma é possível observar que como Presidente Prudente se destaca de maneira expressiva na quantidade de comércios, se torna a cidade que mais se relaciona com a média.

\section{DISCUSSÃO}

Conclui-se que para os imóveis urbanos e para os terrenos, houve uma crescente valorização do preço do metro quadrado, em razão da expectativa dos reflexos da mudança socioeconômica e possivelmente de uma demanda reprimida por 3 anos. Apesar de suas oscilações, percebe-se que as alterações nos preços têm correlação com a política nacional, ou seja, as decisões políticas interferem não apenas na economia, mas em todo o setor imobiliário do Oeste Paulista.

Diante do exposto, conclui-se que o Oeste Paulista passa por um aquecimento do setor urbano, mas para se manter são necessárias condições macroeconômicas consolidadas para os próximos anos.
Para os imóveis rurais, o ganho de mais de $200 \%$ em terras devolutas na região, provém da segurança jurídica, estabelecida em 2019 e não da atividade agrícola. Ao mesmo tempo que, a desvalorização das terras regulamentadas provavelmente corresponde a teoria clássica dos preços relativos, afinal observa-se uma aproximação das duas modalidades de contratos. A diferença atual de 5\%, entre terras regulamentadas e devolutas, é o custo de oportunidade precificado pelo mercado e não um reflexo da rentabilidade da atividade econômica.

Desta forma, pode-se afirmar que há um potencial agrícola no Oeste Paulista e que a atividade rural deve se intensificar nos próximos anos.

Os preços dos imóveis comerciais da região são diretamente influenciados com a oscilação da economia brasileira, visto que em todos os casos em que o PIB obteve uma variação positiva, no semestre seguinte os preços também variaram positivamente e o mesmo ocorreu no caso contrário, nas duas vezes que houve as variações negativas. Assim, pode-se dizer que devido os imóveis desta categoria estarem diretamente relacionados com o comércio da região, esses são afetados conforme a economia em geral oscila.

Observa-se que apesar da relação, nem sempre os preços oscilam na mesma proporção que o PIB, o fenômeno é explicado pela influência direta e ligação da cidade com a economia nacional, existe um loop econômico ou uma retroalimentação entre preço dos imóveis e a 
atividade econômica, monitorar esse movimento possibilita a antecipação de atores econômicos que poderão aumentar seus ganhos aproveitando o delay de alguns mercados locais.

A criação de um canal de informação pode no futuro, reduzir assimetria do mercado, deixar a informação mais acessível e facilitar o investimento e os ganhos nos mercados imobiliários do Oeste Paulista, sejam eles; rurais, comerciais ou residenciais.

\section{AGRADECIMENTOS}

Este trabalho só foi possível, primeiramente, graças a Deus, que concedeu saúde, disposição e benefícios para concluí-lo. Em seguida, à família pelo apoio, paciência e incentivo ao longo de todo o processo da pesquisa e por fim, aos amigos pela compreensão e ajuda em todos os momentos.

Os autores declaram não haver qualquer potencial conflito de interesse que possa interferir na imparcialidade deste trabalho científico.

\section{REFERÊNCIAS}

BERTONCELLO, A. G.; Ó SOUZA, I. S. O modelo Gravitacional do Tecido Social do Oeste Paulista. Colloquium Socialis, v. 2, n. 3 p. 47-52, 2018. https://doi.org/10.5747/cs.2018.v02.n3.s048

DEMYANYK, Y., HEMERT O. V., Understanding the suprime mortgage crisis. The review of financial studies. v. 24, n. 6 p 1848-1880 2011. https://doi.org/10.1093/rfs/hhp033

FIPEZAP-. Tendências do mercado imobiliários, compra e locação de imóveis. 2019. Disponível em: https://fipezap.zapimoveis.com.br/. Acesso em: 02 ago. 2019.

FONSECA, J. J. S. Metodologia da Pesquisa Científica. Fortaleza-CE- Universidade Estadual do Ceará, 2002.

Disponível em: http://www.ia.ufrri.br/ppgea/conteudo/conteud o-2012-1/1SF/Sandra/apostilaMetodologia.pdf

Acesso em: 02 ago. 2019.

GIL, A. C. Métodos e Técnicas de Pesquisa Social. 6. ed. São Paulo: Editora Atlas, 2008. Disponível em:

https://ayanrafael.files.wordpress.com/2011/08/ gil-a-c-mc3a9todos -e-tc3a9cnicas-de-pesquisasocial.pdf. Acesso em: 02 ago. 2019.

IBGE. Instituto Brasileiro de Geografia e Estatística. Produto Interno Bruto - PIB, 2019.

Disponível em: https://www.ibge.gov.br/explica/pib.php. Acesso em: 02 ago. 2019.

IPEADATA. Produto interno bruto (PIB) real. 2019.

Disponível em: http://www.ipeadata.gov.br/ExibeSerie.aspx?seri d=38414. Acesso em: 02 ago. 2019.

JP MORGAN. Brazilian Housebuilders 101: The 2011 Handbook. São Paulo. 2011.

MOSTAFA A.; WONG, F. K. ; HUI C. M., Relationship between Housing affordability and Economic Development in Mainland China: Case of Shanghai. Journal of Urban Planning and Development. v. 132, n. 1, 2006. https://doi.org/10.1061/(ASCE)07339488(2006)132:1(62) 